\title{
Knowledge of SLE among Health Care Providers and Non-Medical Attendants of Helwan University Hospital
}

\author{
HASSAN A.M. ELSONBATY, M.D.** and TAHSEEN SAMIR MOHAMMED, M.D.* \\ The Departments of Public Health \& Community Medicine and Rheumatology \& Rehabilitation, Faculty of Medicine, \\ Al-Azhar* and Helwan** Universities
}

\begin{abstract}
Background: Systemic lupus erythematosus (SLE) is a chronic, multisystem; autoimmune disorderattacks any part of the body including the vital organs. Damage, dysfunction and complications by comorbidities increase due to delay in diagnosis. It has a significant mortality and morbidity.

Aim of Study: This study aimed to assess knowledge regarding SLE among the Egyptian population attending Helwan University Hospital in order to improve quality of health.

Patients and Methods: A cross-sectional, hospital-based study conducted on 720 subjects (63 Health care providers and 657 Non-medicals). The questionnaire consisted of the following parts (demographic data, general knowledge, risk factors, diagnostic methods, therapies, and complication). Reliability Testand validity of the questionnaire were determined. The study was carried at Al-Azhar University Hospitals during the period between January 2020 till January 2021.

Results: The study showed that median grand total knowledge score percentage for participants was $28 \%$ (poor knowledge). There was statistically significant higher knowledge score about treatment options in female vs. male participants ( $25 \%$ vs. $12.5 \%$ ). There was a statistically significant higher general and grand total knowledge scores in health care providers vs. those with non-medical professions (53.3\% vs. $33.3 \%$ and $30 \%$ vs. $26 \%$, respectively).

Conclusion: This study revealed that awareness of SLE among participants was inadequate particularly among less educated, there are so many misconceptions about essential information of this serious disease. The comprehensive national study is recommended to clarify the knowledge about SLE.
\end{abstract}

Key Words: Systemic lupus erythematosus - Knowledge, Health care providers - Non-medical attendants.

\section{Introduction}

SYSTEMIC lupus erythematosus (SLE) is a chronic multi-system autoimmune disease [1]. Impacting the physical well being and health related quality of life (HRQOL) of patients [2]. In which immune

Correspondence to: Dr. Hassan A.M. Elsonbaty, E-Mail: Hassan.rheumatology16@gmail.com system attacks various organs, causing damage and dysfunction [3]. Some patients have mild disease, which can be treated with simple medications whereas others can have serious, life-threatening

With a significantly higher mortality in SLE patients, developing chronic damage, Awareness is a major goal in management. Flares are a common feature of SLE and can result in organ failure

The cause of autoimmune diseases is not fully understood, but the hidden process in SLE is that the immune system mistakenly attacks healthy tissue by using complexes or cytotoxic antibodies

SLE is one of several diseases known as "the great imitator" because it often mimics or is mistaken for other illnesses [7].

SLE has unevenness at the onset that making correct and early diagnosis is challenging [8] .

Assessing knowledge on SLE can lead to the identification of deficient areas of information and, thus, would aid in devising education programs. To our knowledge, this is the first study that specifically aimed to measure the knowledge of SLE among Egyptian adults. Provided that it has an acceptable reliability and validity, the questionnaire can be used in exploring the level of knowledge on SLE among sample of the Egyptian population.

Awareness about SLE may help in early diagnosis and to minimize its complications and severity [9].

Disease awareness has also been shown to be an important determinant of outcome in SLE, however: Poorer knowledge is associated with 
greater physical and mental disorders [10]. While increased disease awareness within the family and the community has been implicated an improvedquality of life and reduced frequency of flares in patients [11-13].

\section{Patients and Methods}

A cross-sectional questionnaire was designed to study knowledge of general population on Systemic Lupus Erythematosus. This questionnaire was conducted on 720 Egyptian participants from those attending Helwan University Hospital between December 2020 and February 2021. Ethical clearance has been obtained from REC-FMHU: 78-2020. The participants were 63 Health care providers ( 9 males, 54 females) and 657 Nonmedicals (180 males, 477 females). Written informed consent was obtained from all the participants.

The questionnaire consisted of the following parts (demographic data, general knowledge, risk factors, diagnostic methods, therapies, and complication [14].

\section{Reliability test and validity of the questionnaire:}

Kuder Richardson 20 (KR20) was run on items collected from a pilot study conducted on 10 health care providers to measure test reliability of interitem consistency. The coefficient was acceptable for all domains with only one change for the question about "SLE is complicated by thrombocytopenia" to be about "SLE can affect complete blood count". The final coefficients are reported in Table (1) and showed that KR20 values were above 0.75 (acceptable value) for all domains and below 0.90 (No redundant items).

Table (1): Reliability test of the questionnaire.

\begin{tabular}{lc}
\hline Domain & KR20 coefficient \\
\hline General & 0.887 \\
Symptom & 0.802 \\
Diagnosis & 0.863 \\
Complications & 0.794 \\
Treatment & 0.791 \\
Overall & 0.849 \\
\hline
\end{tabular}

The questionnaire was administered under the supervision of researchers during the study period. Questions weregiven one score for the correct answers and zero for incorrect answers. The total score was changed to a percentage. Those who had $50 \%$ or greater were considered to have good knowledge while those who got less than $50 \%$ were classified to have poor knowledge of SLE.

\section{Statistical analysis:}

Data were coded, entered and analyzed using SPSS version 22. Categorical variables were presented as frequencies and percentages and continuous variables as means and standard deviations. The associations between categorical variables were analyzed using Pearson's Chi-squared test \pm continuity correction. A simple logistic regression analysis was initially used to explore the data. And 95\% confidence intervals (95\% CI) were calculated, Statistical significance for all associations was considered being at $p<0.05$.

\section{Results}

This study involved 720 participants with a median age of 33 years S.D, 531 (73.8\%) were female and 189 (26.3\%) were male. Participants were classified into 4 subgroups: Group 1: male health care providers $(\mathrm{N}=9)$, group 2: male with non-medical professions $(\mathrm{N}=180)$, group 3: female health care providers $(\mathrm{N}=54)$, group 4: female with non-medical professions $(\mathrm{N}=477)$. There was statistically significant difference between male and female participants in the distribution of marital status (married status was more in female and single status was more in male), education level (basic level was more in female), and profession (health provider profession was more in female) as shown in Table (2).

Table (2): Socio-demographic characteristics of the study participants.

\begin{tabular}{|c|c|c|c|c|}
\hline Characteristic & Total & Male & Female & $\begin{array}{c}p- \\
\text { value }\end{array}$ \\
\hline $\mathrm{N}$ & 720 & 189 & 531 & \\
\hline Age (years)* & $33(25-44)$ & $33(24-43)$ & $33(25-44)$ & 0.194 \\
\hline $\begin{array}{l}\text { Marital status } \$ \text { : } \\
\text { Married } \\
\text { Single }\end{array}$ & $\begin{array}{l}511(71 \%) \\
209(29 \%)\end{array}$ & $\begin{array}{l}119(63 \%) \\
70(37 \%)\end{array}$ & $\begin{array}{l}392(73.8 \%) \\
139(26.2 \%)\end{array}$ & 0.005 \\
\hline $\begin{array}{l}\text { Education level: } \\
\text { Basic } \\
\text { Secondary } \\
\text { University } \\
\text { Postgraduate }\end{array}$ & $\begin{array}{l}57(7.9 \%) \\
164(22.8 \%) \\
466(64.7 \%) \\
33(4.6 \%)\end{array}$ & $\begin{array}{l}6(3.2 \%)^{\mathbf{a}} \\
47(24.9 \%) \\
129(68.3 \%) \\
7(3.7 \%)\end{array}$ & $\begin{array}{l}51(9.6 \%) \mathbf{b} \\
117(22 \%) \\
337(63.5 \%) \\
26(4.9 \%)\end{array}$ & 0.034 \\
\hline $\begin{array}{l}\text { Profession: } \\
\text { Health care } \\
\text { provider } \\
\text { Non-medical }\end{array}$ & $\begin{array}{l}63(8.8 \%) \\
657(91.3 \%)\end{array}$ & $\begin{array}{l}9(4.8 \%) \\
180(95.2 \%)\end{array}$ & $\begin{array}{l}54(10.2 \%) \\
477(89.8 \%)\end{array}$ & 0.024 \\
\hline
\end{tabular}

There was that median grand total knowledge score $\%$ for participants was $28 \%$ (poor knowledge). There was statistically significantly higher knowledge score about treatment options in female 
vs. male participants ( $25 \%$ vs. $12.5 \%)$. For other domains and for the grand total score, there was no statistically significant difference between male and female participants (Table 3; Fig. 1).

Table (3): Knowledge scores of the study participants (male vs. female).

\begin{tabular}{llccc}
\hline Knowledge score $(\%)$ & \multicolumn{1}{c}{ Total } & \multicolumn{1}{c}{ Male } & Female & $p$-value \\
\hline $\mathrm{N}$ & \multicolumn{1}{c}{720} & 189 & 531 & \\
General & $40(13.3-66.7)$ & $33.3(13.3-66.7)$ & $40(13.3-66.7)$ & 0.880 \\
Symptom & $18.2(0.0-36.4)$ & $18.2(0.0-36.4)$ & $18.2(0.0-36.4)$ & 0.880 \\
Diagnosis & $20(0.0-80)$ & $20(0.0-80)$ & $20(0.0-80)$ & 0.179 \\
Treatment & $25(12.5-25)$ & $12.5(12.5-25)$ & $25(12.5-25)$ & $<\mathbf{0 . 0 0 1}$ \\
Complications & $9.1(0.0-27.3)$ & $9.1(0.0-18.2)$ & $9.1(0.0-27.3)$ & 0.273 \\
Grand total & $28(20-36)$ & $26(18-32)$ & $28(20-36)$ & 0.097 \\
\hline
\end{tabular}

- Data expression [Test of significance]: Median (25th percentile - 75th percentile) [Mann-Whitney Test].

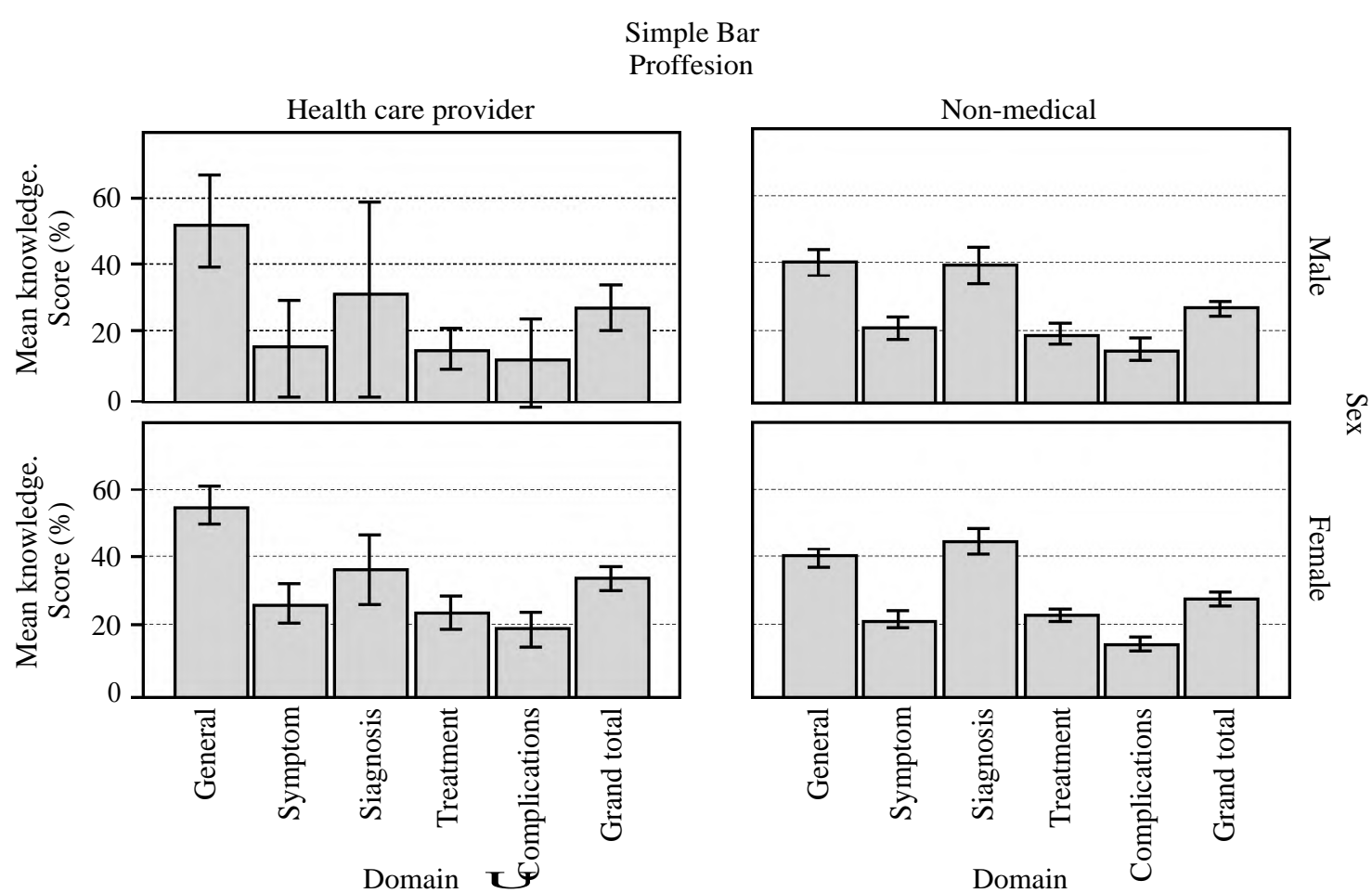

Error Bars : $955 \%$ CI

Fig. (1): Knowledge scores of the study participants.

There was a statistically significantly higher general and grand total knowledge scores in health care providers vs. those with non-medical profes- sions $(53.3 \%$ vs. $33.3 \%$ and $30 \%$ vs. $26 \%$, respectively). There was no statistically significant difference for other domains (Table 4; Fig. 1).

Table (4): Knowledge scores of the study participants (Medical vs. Non-Medical).

\begin{tabular}{lccc}
\hline $\begin{array}{l}\text { Knowledge } \\
\text { score }(\%)\end{array}$ & $\begin{array}{c}\text { Medical } \\
\text { profession }\end{array}$ & $\begin{array}{c}\text { Non-medical } \\
\text { profession }\end{array}$ & $\begin{array}{c}p- \\
\text { value }\end{array}$ \\
\hline $\mathrm{N}$ & 63 & 657 & \\
General & $53.3(33.3-73.3)$ & $33.3(13.3-66.7)$ & $<\mathbf{0 . 0 0 1}$ \\
Symptom & $18.2(0.0-45.5)$ & $18.2(0.0-36.4)$ & 0.172 \\
Diagnosis & $20(0.0-60)$ & $20(0.0-80)$ & 0.186 \\
Treatment & $25(12.5-25)$ & $25(12.5-25)$ & 0.635 \\
Complications & $9.1(0.0-27.3)$ & $9.1(0.0-27.3)$ & 0.145 \\
Grand total & $30(26-40)$ & $26(18-36)$ & $\mathbf{0 . 0 0 2}$ \\
\hline
\end{tabular}

- Data expression [Test of significance]: Median (25th percentile - 75th percentile) [Mann-Whitney Test]. 
There was a statistically significant difference in general, treatment and grand total knowledge scores between the 4 groups. Pairwise comparisons revealed that both general and grand total scores were statistically significantly higher in female health care providers vs. non-medical professions (male and female). The scores were also higher than male health care providers, but the difference did not achieve a statistical significance. Treatment score statistically significantly higher in female vs. male health care providers but no statistically significant difference between other subgroups (Table 5; Fig. 1).

As demonstrated in Fig. (2), it showed that predictors of the likelihood of having knowledge score of $>50$ of the 720 participants, only 42 (5.8\%) achieved a score that is equal to or exceeding $50 \%$.

Table (5): Knowledge scores of the study participants (4 groups): Compares between the 4 groups as regards knowledge scores.

\begin{tabular}{|c|c|c|c|c|c|}
\hline Knowledge score $(\%)$ & Group 1 & Group 2 & Group 3 & Group 4 & $p$-value \\
\hline $\mathrm{N}$ & 9 & 180 & 54 & 477 & \\
\hline General & $40(33.3-70)^{\mathbf{a}^{\prime} \mathbf{b}}$ & $33.3(13.3-66.7) \mathbf{a}$ & $53.3(33.3-73.3) \mathbf{b}$ & $33.3(13.3-60) \mathbf{a}$ & $<0.001$ \\
\hline Symptom & $18.2(0.0-27.3)$ & $18.2(0.0-36.4)$ & $27.3(6.8-45.5)$ & $18.2(0.0-36.4)$ & 0.314 \\
\hline Diagnosis & $20(0.0-60)$ & $20(0.0-80)$ & $20(0.0-65)$ & $40(0.0-80)$ & 0.274 \\
\hline Treatment & $12.5(12.5-25)^{\mathbf{a}} \mathbf{b}$ & $12.5(12.5-25) \mathbf{a}$ & $25(12.5-25)^{\mathbf{a}^{\prime} \mathbf{b}}$ & $25(12.5-25) \mathbf{b}$ & 0.001 \\
\hline Complications & $0.0(0.0-22.7)$ & $9.1(0.0-18.2)$ & $18.2(0.0-27.3)$ & $9.1(0.0-27.3)$ & 0.246 \\
\hline Grand total & $30(20-33) \mathbf{a}^{\mathbf{a}} \mathbf{b}$ & $26(18-32) \mathbf{a}$ & $31(25.5-42) \mathbf{b}$ & $26(18-36) \mathbf{a}$ & 0.005 \\
\hline
\end{tabular}

- Data expression [Test of significance]: Median (25th percentile - 75th percentile) [Kruskal-Wallis Test].

Grand total knowledge score.

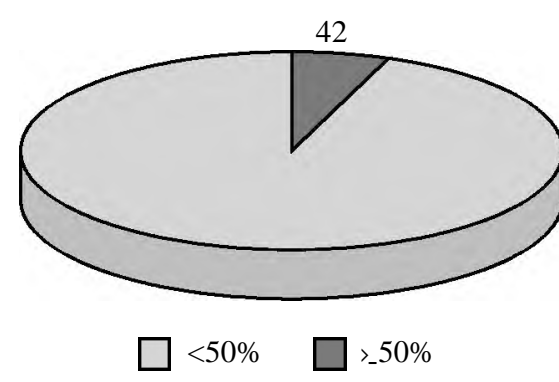

Fig. (2): Grand total knowledge score.
This study showed that higher education level (University/postgraduate) vs. lower education level (basic/secondary) was the only statistically significant independent predictor of the likelihood that 678 participant will score at least $50 \%$. The model was statistically significant $\left[\chi^{2}=13.991, p=0.016\right]$. The model correctly classified $94.2 \%$ of participants with $100 \%$ specificity. Participants with higher education level have 6 times higher odds that their score will be at least $50 \%$ (Table 6).

Table (6): The results of binary logistic regression analysis that was run to ascertain the effects of female sex, medical profession, married status, age, and a university level of education or higher on the likelihood that participants will score at least $50 \%$.

\begin{tabular}{|c|c|c|c|c|c|c|}
\hline \multirow{2}{*}{ Predictor } & \multicolumn{3}{|c|}{ Univariate } & \multicolumn{3}{|c|}{ Multivariate } \\
\hline & $p$-value & COR & $95 \% \mathrm{CI}$ & $p$-value & COR & $95 \% \mathrm{CI}$ \\
\hline Sex: & 0.466 & & & 0.305 & & \\
\hline Male & & $\mathrm{R}$ & $\mathrm{R}$ & & $\mathrm{R}$ & $\mathrm{R}$ \\
\hline Female & & 1.3 & $0.62-2.8$ & & 1.5 & $0.69-3.2$ \\
\hline Profession: & 0.855 & & & 0.493 & & \\
\hline Non-medical & & $\mathrm{R}$ & $\mathrm{R}$ & & $\mathrm{R}$ & $\mathrm{R}$ \\
\hline Medical & & 1.1 & $0.38-3.2$ & & 0.67 & $0.21-2.1$ \\
\hline Age & 0.506 & 1.009 & $0.98-1.04$ & 0.482 & 1.02 & $0.97-1.06$ \\
\hline Marital status: & 0.444 & & & 0.202 & & \\
\hline Single & & $\mathrm{R}$ & $\mathrm{R}$ & & $\mathrm{R}$ & $\mathrm{R}$ \\
\hline Married & & 1.3 & $0.64-2.8$ & & 0.50 & $0.17-1.45$ \\
\hline Education level: & 0.005 & & & 0.002 & & \\
\hline Lower & & $\mathrm{R}$ & $\mathrm{R}$ & & $\mathrm{R}$ & $\mathrm{R}$ \\
\hline Higher & & 4.5 & $1.6-12.7$ & & 6 & $1.9-18.6$ \\
\hline
\end{tabular}

$\mathrm{R}=$ Reference category. $\quad \mathrm{CI}=$ Confidence interval. $\quad \mathrm{COR}=$ Crude odds ratio. $\quad \mathrm{OR}=\mathrm{Odds}$ ratio 


\section{Discussion}

Significant differences between the scores of the health care providers and those with nonmedical professions indicated that the questionnaire had satisfactory construct validity, even when taking into account the skewed gender and age characteristics ofthe groups. The female scored higher knowledge about treatment options.

According to general knowledge items of SLE, our study found that $28 \%$ have previously heard the term SLE. It is important that awareness campaign should be carried out. There was a higher knowledge about treatment options in female vs. male participants ( $25 \%$ vs. $12.5 \%$ ).

It also showed a higher knowledge in health care providers vs. those with non-medical professions $(53.3 \%$ vs. $33.3 \%$ and $30 \%$ vs. $26 \%$, respectively) and higher knowledge about treatment options in female vs. male participants $(25 \%$ vs. $12.5 \%)$.

To our knowledge, this is the first Egyptian scientific evaluation of such awarenessof SLE among general population. Few comparative data are available for other population. A single timepoint marketing study carried out in the United States, based on almost 3000 randomly selected respondents, showed an unexpectedly high awareness of $86 \%$ [15]. In India, a study (2017) among the general population to assess their SLE awareness and knowledge found that the majority of participants had insufficient knowledge of its status as a rare disease that occurs in the population [16]

In Saudi Arabia, a cross-sectional study conducted among 400 participants; $56.8 \%$ of patients had heard the term "SLE", most of the participants did not know anyone with SLE $(61.5 \%)$ and the majority did not know that SLE is not contagious (48.2\%) but could be fatal (43.5\%). Most believed that SLE was a hereditary disease and classified SLE in this way (29.8\%). They also did not know that SLE can affect many organs in the body $(44.5 \%)$ and $26.8 \%$ believed that only the kidney could be affected by systemic lupus erythematosus [17].

In Al-Dammam, another study was carried out among 240 participants, the study reported that the majority (54\%) have never heard of SLE while $(46 \%)$ of respondents have previously heard of SLE, (52\%) of participants didn't know if SLE affects any organ of the body or not and (23\%) thought SLE is not associated with any organ involvement. (69\%) didn't know if the disease is fatal or not while (21\%) participants believe that SLE is a fatal disease [18].

Another study was conducted among Six hundred thirty participants in King Saud University, the results showed that $40 \%$ have previously heard the term SLE, 28\% identified it as an autoimmune disease, while $(15.5 \%)$ thought it is an infectious disease [19]

Due to differences in healthcare system and awareness campaignsin United States. Our study results differ from that applied in United States.

On the other hand our study results are proximately agree with other studies due to near culture and less awareness campaigns about SLE.

An intensivenational lupus awareness campaign should be carried out involving television, radio, social media, newspapers, magazines, and posters in public transport systems and public buildings.

Among the limitations of this study was the low number of males in comparison to females. It is generally agreed that educated participants demonstrate significantly better knowledge. It is tempting to suggest that if this questionnaire was used in exploring the knowledge level of the general public on SLE, more questions would be incorrectly answered by thepeople.

In conclusion, this study showed that this survey is beneficial to the society as it help people to become aware of this disease. Although they may have basic information about it, some of them may not have sufficient knowledge of it, as a serious disease. The questionnaire assessed in this study proved to be a valid and a reliable tool to measure the knowledge, sinceit is easy to understand and it can be completed by the participants in a short time. Future directions for awareness about the nature of the disease, its course, management and outcome should be carried out.

\section{Conflict of interest: Non.}

\section{Funding:}

This research did not receive any specific grant from funding agencies in the public, commercial, or not-for-profit sectors.

\section{References}

1- KURIYA B., GLADMAN D.D., IBANEZ D. and UROWITZ M.B.: Quality of life over time in patients with systemic lupus erythematosus. Arthritis Rheum., 59 (2): 181-185, 2008.

2- YAZDANY J. and YELIN E.: Health-related quality of life and employment among persons with systemic lupus 
erythematosus. Rheum. Dis. Clin. North Am., 36: 15-32, 2010.

3- DANCHENKO N., SATIA J.A. and ANTHONY M.S.: Epidemiology of systemic lupus erythematosus: A comparison of worldwide disease burden. Lupus, 15 (5): 308318, 2006.

4- LISNEVSKAIA L., MURPHY G. and ISENBERG D.: Systemic lupus erythematosus. Lancet, 384 (9957): 1878188, 2014.

5- CONTI F., CECCARELLI F., PERRICONE C., LECCESE I., MASSARO L., PACUCCI V.A., et al.: The chronic damage in systemic lupus erythematosus is driven by flares, glucocorticoids and antiphospholipid antibodies: Results from a monocentric cohort. Lupus Jun., 25 (7): 719-726, 2016.

6- FERNANDEZ D. and KIROU K.A.: What causes lupus flare? Curr. Rheumatol. Rep., 18 (3): 14, 2016.

7- SHIKHA A.S., LU Y., CHEN M.J., AKBAR M., ZEUMER L., RITTER A., et al.: Alpha1 antitrypsin inhibits dendritic cell activation and attenuates nephritis in a mouse model of lupus. PLoS One, 11 (5): e 0156583, 2016.

8- LEE H.T., WU T.H., LIN C.S., LEE C.S., YAU HUEI WEI, CHANG YOUH TSAI, et al.: The pathogenesis of systemic lupus erythematosus from the view point of oxidative stress and mitochondrial dysfunction. Mitochondrion, 30 (9): 1-7, 2016.

9- WADEE S., TIKLY M. and HOPLEY M.: Causes and predictors of death in South Africans with systemic lupus erythematosus. Rheumatol., 46 (9): 1487-1491, 2007.

10- JALALI M., HRIZ H., CHERIF Y., MARZOUK S., SNOUSSI M., FRIKHA F., et al.: Causes and outcome of hospitalizations in Tunisian patients with systemic lupus erythematosus. Lupus Sci. Med., 1 (1): e000017, 2014.
11- RAHMAN A., ISENBERG D.A.: Systemic lupus erythematosus: Review article. N. Engl. J. Med., 358 (9): 929-939, 2012.

12- KONTTINEN Y.T., SANTAVIRTA N., HONKANEN V., SANDELIN S., SCHAUMAN L. and GRÖNBLAD M.: Systemic lupus erythematosuspatient guide: Influence on knowledge of the disease. Ann. Rheum. Dis., 50: 900902, 1991.

13- WEKKING E.M., VINGERHOETS A.J.M., VAN DAM A.P., NOSSENT J.C. and SWAAK A.J.G.: Daily stressors and systemic lupus erythematosus: A longitudinal analysisfirst findings. Psychother Pshchosom, 55: 108-113, 1991.

14- CARMINES E.G. and ZELLER R.A.: Reliability andvalidity assessment. London: Sage Publications, $72 \mathrm{p}$. (Quantitative applications in the social sciencesseries no.17), 1979.

15- LAHITA R.G.: Special report: Adjusted lupus prevalence. Results of a marketing survey by the Lupus Foundation of America. Lupus, 4: 450-453, 1995.

16-ZAABA NAAB and GHEENA A.: To study the awareness of the general public on Systemic Lupus Erythematosus (SLE). Int. J. Curr. Res., 9 (2): 46382-46385, 2017.

17- HAIKEL K.A.B. and TULAIHI B.A.: Awareness of systemic lupus erythematosus among primary health care patients in Riyadh, Saudi Arabia. Open Access Maced J. Med. Sci., 6 (12): 2386-2392, 2018.

18- ALHARB M.: Public awareness of systemic lupus erythematosus in Al- Dammam city in Saudi Arabia. Egy. J. Hosp. Med., 70 (11): 1891-1893, 2018.

19- OMAIR M.A., ALOHALY R.Y., ALASHGAR L.M., AL OHALI S.M. and ABDULKARIM F.A.: Awareness and misconceptions of female students in King Saud University on systemic lupus erythematosus. Rheumatol., 5 (7): 165, 2015. 


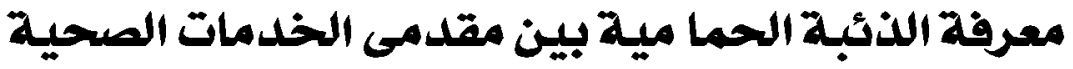

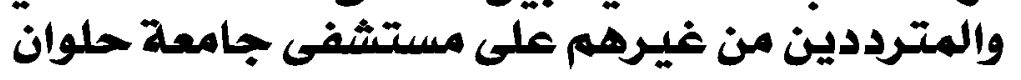

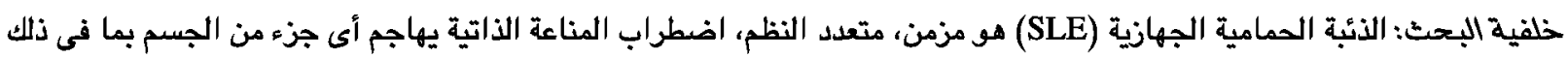
الأعضاء الحيوية. الضرد والخلل الوظيفى والمضاعفات الناجمة عن الأمراض المرضية زيادة بسبب التأخير في التشخيص، لديها معدل وفيات واعتلال كبير.

الهدف من البحث: هدفت هذه الدراسة إلى تقييم المعرفة المتعلقة بالأمراض البرية غير الصحية بين مقدمى الخدمة والمترددين على

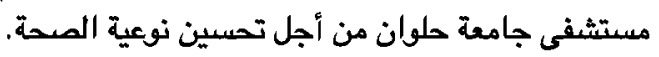

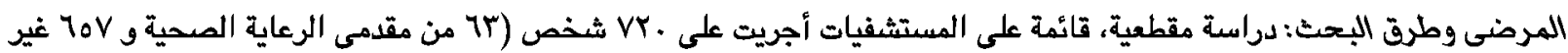

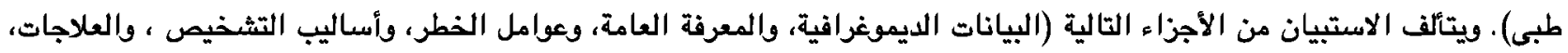

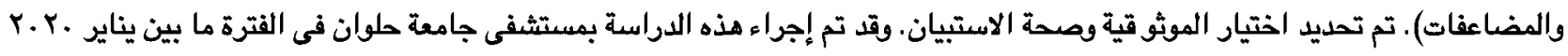

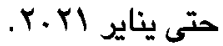

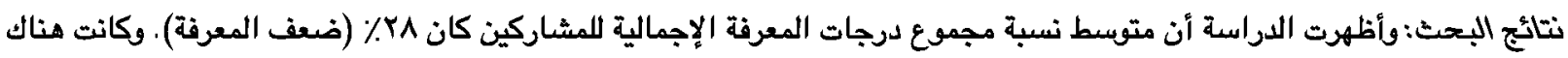

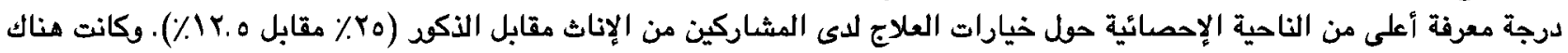

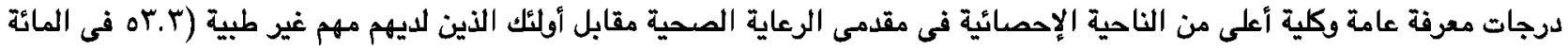

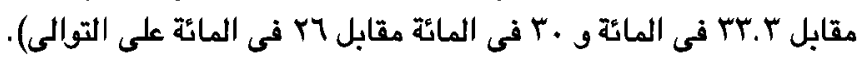

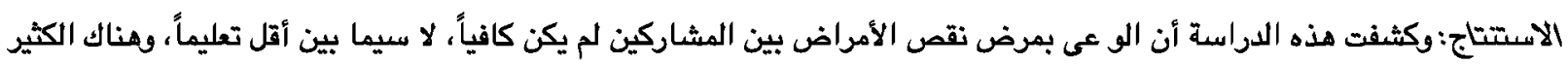

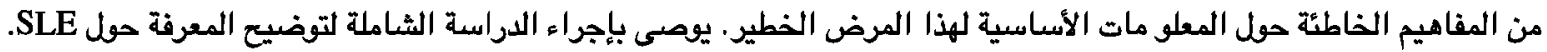

